\title{
ENSINO DE GEOGRAFIA E ARTES VISUAIS NA EDUCAÇÃO BÁSICA: DIÁLOGOS POSSÍVEIS ARTICULADOS COM MÍDIAS CONTEMPORÂNEAS
}

\author{
Yves de Sousa Silva ${ }^{1}$ \\ Kelly Bianca Clifford Valença ${ }^{2}$
}

\begin{abstract}
Resumo: Conciliando necessidades de ensino previstas no currículo com desejos de aprendizagens dos alunos, o trabalho aqui narrado foi realizado na Escola Municipal de Tempo Integral Mônica de Castro Carneiro, e constituiu uma maneira de contribuir para que conceitos geográficos construídos em sala fossem mais facilmente compreendidos pelos estudantes. Associando tecnologias contemporâneas à mediação pedagógica, alunos de uma turma de $6^{\circ}$ ano foram instrumentalizados a elaborar uma produção artística, audiovisual, sobre o bullying, tema elegido por eles mesmos e incorporado à discussão sobre o espaço geográfico. Nesta tessitura, tomando o espaço escolar como cenário, uma analogia com métodos de operar da geografia contribuiu para que houvesse um deslocamento da condição de receptores passivos para atores do conhecimento, ao protagonizarem, fílmicamente, questôes sociais que cerceiam o cotidiano. Uma vez concluídas as etapas de produção que compóem um vídeo curta-metragem, a sociabilização deste relato em espaços que transcendem o escolar motivou os escritos aqui apresentados.
\end{abstract}

Palavras-chave: Ensino de Geografia. Artes Visuais. Mídias Contemporâneas.

1 Mestre em Engenharia Urbana pela Universidade Federal da Paraíba (UFPB), Licenciado e Bacharel em Geografia pela mesma Instituição. Atualmente é professor de Geografia e Mídias Contemporâneas na Rede Municipal de Educação e Esporte (SME) de Goiânia.

2 Doutora em Educação pela Universidade Federal de Goiás (UFG), Mestre em Arte e Cultura Visual pela mesma Instituição, Especialista em Arteterapia pela Faculdade Mauá de Brasília e Licenciada em Desenho e Plástica pela Universidade Federal de Pernambuco (UFPE). Atualmente é Professora Adjunto II do Centro de Ensino e Pesquisa Aplicada à Educação (CEPAE) da Universidade Federal de Goiás (UFG). 


\title{
TEACHING GEOGRAPHY AND VISUAL ARTS IN BASIC EDUCATION: POSSIBLE DIALOGUES ARTICULATED WITH CONTEMPORARY MEDIA
}

\begin{abstract}
By reconciling teaching needs foreseen in the curriculum with learning desires of students, this work was carried out at the Municipal School of Integral Time Mônica de Castro Carneiro and contributed to the geographic concepts built in the classroom were more easily understood by the students. Associating contemporary technologies with pedagogical mediation, students of a 6th grade class were instructed in producing an artistic and audiovisual production about bullying, a theme chosen by themselves and incorporated into the discussion about geographic space. In this context, taking the school space as a scenario, an analogy with methods of operating of the geography contributed to a displacement from the condition of passive recipients to knowledge actors, by filming, in a filmmatic way, social issues that retrenches everyday life. Once the production stages that make up a short video are concluded, the sociabilization of this story in spaces that transcend school has motivated the writings presented here.
\end{abstract}

Keywords: Teaching Geography. Visual arts. Contemporary media.

\section{Introduçáo}

O trabalho em pauta fundamentou-se na reação desestimulada de alunos da Educação Básica da Escola Municipal de Tempo Integral Mônica de Castro Carneiro, frente ao contexto escolar no qual estavam inseridos. Esta conjuntura envolvia problemas não só de ordem financeira como também pedagógica, ao passo que a realidade dos estudantes nem sempre eram tomadas como ponto de partida para pensar o processo de ensino-aprendizagem. Com efeito, após um trabalho denominado por Tavares (2003) como 'escuta sensível', chegouse à conclusão de que havia, naquele cenário, uma carência de ações capazes de promover a ampliação dos conhecimentos curriculares de uma maneira dinâmica, considerando escolhas e preferências dos estudantes. Após algumas reflexões buscando responder à pergunta: 'como fazer uso dos recursos e condições disponíveis na escola para otimizar a construção do conhecimento geográfico, de modo atrativo e estimulante?' Chegamos ao consenso de que a implementação de uma proposta de trabalho com o uso de tecnologias contemporâneas, capazes de aliar questões pedagógicas e curriculares à atividades onde os alunos pudessem se ver protagonizando experiências fílmicas, seria uma maneira de responder à pergunta inicialmente lançada, dado o interesse que os estudantes demonstravam por esses recursos.

Uma vez organizado um esboço de trabalho, os alunos sinalizaram desejo em explorar um tema que traduz um recorrente problema social na contemporaneidade: o bullying. Motivo pelo qual o desafio de aliar a implementação da proposta ao currículo previsto para a disciplina geografia levou-nos a agregar ao projeto o recorte 'Espaço Geográfico'.

Considerando o pensamento de Santos (2004), ao defender que o caráter social do espaço deveria ser o principal enfoque dos que representam a área da 
geografia, a delimitação de conteúdo aqui apresentada justifica-se ao passo que sendo o espaço geográfico aquele constituído e constantemente transformado pela ocupação do homem na Terra, configura uma possibilidade pedagógica de pensar questões sociais cotidianas dos estudantes. Colocando a perspectiva de Santos (2004) em diálogo com a ótica de Tavares (2003, p. 57), foi preciso manter em mente durante o planejamento desta ação que "[...] o espaço não é neutro, mas sempre educativo", questão que conduziu o nosso olhar a um trabalho que, em verdade, nasceu de reivindicações lançadas nos corredores da escola, espaço educativo habitado por professores e alunos cotidianamente.

Assim, constituíram objetivos de aprendizagem do trabalho:

\section{Geral:}

Ampliar a experiência escolar de estudantes da Educação Básica, relativa à construção de conhecimentos geográficos, artísticos e tecnológicos, empoderandoos ao exercício da cidadania e ressignificando as suas respectivas atitudes perante o mundo.

\section{Específicos:}

Estimular a criticidade no que tange às causas e implicações da ação humana diante do bullying, especialmente no espaço escolar;

Viabilizar a conscientização sobre a responsabilidade social das nossas escolhas e intervenções no espaço vivido, enquanto cidadãos, considerando direitos e deveres;

Produzir um vídeo curta-metragem, otimizando os repertórios tecnológicos e cognitivos dos estudantes ao articular os conteúdos deste trabalho com as especificidades implicadas em uma produção artística, audiovisual.

\section{Desenvolvimento}

O trabalho aqui descrito foi desenvolvido e concluído na Escola Municipal de Tempo Integral Mônica de Castro Carneiro, na disciplina geografia, durante o ao de 2016, com 24 alunos de uma turma do $6^{\circ}$ ano que perpassavam a faixa etária dos 11 anos de idade na ocasião.

A estrutura organizacional da escola em questão pauta-se na dinâmica de Ciclos de Formação e Desenvolvimento Humano por ser esta a estrutura adotada nas Instituições de Tempo Integral da Secretaria Municipal de Educação e Esporte (SME) de Goiânia. Trata-se de uma concepção de formação de sujeitos omnilateral em sua relação com o mundo do trabalho, ou seja: que valoriza a formação humana na sua globalidade, considerando o educando nas suas várias dimensões: física, psíquica, cognitiva, afetiva, ética, estética, social, emocional, dentre outras. 


\section{Diagnóstico}

Após uma sondagem oral sobre os conhecimentos prévios dos alunos, foi possível constatar que muito embora houvesse o interesse de os mesmos trabalharem com a elaboração de vídeos curtas-metragens, os repertórios cognitivos relativos a essa 'linguagem' tão específica eram superficiais. Foi possível verificar com o diagnóstico inicial que cerca de $20 \%$ dos alunos, inclusive, nunca tinha ido ao cinema na vida. Os resultados mais relevantes da sondagem sinalizaram que os alunos:

- Relacionavam a ideia de espaço geográfico unicamente à paisagens urbanas e/ou naturais;

- Apresentavam poucos conhecimentos específicos sobre produções audiovisuais;

- Integravam cerca de 20\% que nunca tinham ido ao cinema, apesar de possuírem 11 anos de vida em sua maioria.

Uma vez planejada e adotada a proposta de elaboração de um vídeo curtametragem associado aos conteúdos aqui expostos, as seguintes etapas de trabalho foram desenvolvidas:

- Levantamento de recursos técnicos disponibilizados pela escola;

- Planejamento dos conteúdos visando maneiras de explorá-lo fílmica e pedagogicamente;

- Roda de conversa objetivando a sondagem dos conhecimentos prévios dos alunos;

- Aulas expositivas dialogadas, teórico-práticas, sobre os conteúdos selecionados;

- Pesquisas em ambiente informatizado e biblioteca;

- Criação e elaboração oral e escrita de um roteiro cinematográfico, culminando com o processo de 'roteirização', isto é: a transformação de uma ideia em formato audiovisual;

- Organização escrita da sinopse fílmica;

- Escolhas de personagens, cenários, figurinos e adereços;

- Ensaios, filmagens e edição;

- Exposição dos filmes dentro e fora da comunidade escolar (incluindo o espaço digital);

- Avaliação do processo e autoavaliação;

Destarte, experimentações cinematográficas articuladas com os conteúdos trabalhados foram tomadas como o 'meio' e o processo de formação integral do indivíduo como o 'fim', de tal modo que o fazer não estava dissociado de intencionalidade pedagógica e de objetivos de aprendizagens bem definidos. Dito de outro modo, não foi o 'fazer pelo fazer' e nem tampouco a geografia à serviço 
de uma produção audiovisual, mas, justamente o contrário: os recursos, meios e técnicas à serviço do ensino de geografia com todas as implicações educativas que isto pressupõe no processo de formação integral do sujeito.

Para tanto, análises fílmicas e pesquisas realizadas no ambiente informatizado constituíram alguns dos materiais utilizados como fonte de pesquisa.

Um desafio vivenciado foi a carência de recursos técnicos essenciais ao desenvolvimento do projeto, tais como: câmeras, tripés e computadores que possibilitassem edições audiovisuais. Diante destas dificuldades, o processo pedagógico se deu de maneira colaborativa, contando com o apoio e equipamentos pessoais do grupo, onde após um levantamento coletivo conseguimos contar efetivamente com: 1 notebook compatível com o trabalho de edição audiovisual, 1 câmera fotográfica/filmadora, 1 aparelho celular, 1 tripé e 1 aparelho data show.

No intento de ampliar os repertórios visuais e culturais dos estudantes, exposições, análises e discussões de filmes e vídeos de diferentes gêneros e temas integraram etapas de trabalho que permearam todo o desdobramento do projeto, inspirando muitas escolhas tanto em relação à escrita do roteiro quanto à organização de cenários e adoção de figurinos. Além disto, o vídeo intitulado ' $O$ Bullying Nosso de Cada Dia, realizado com uma turma de $5^{\circ}$ ano em 2014 também foi adotado como instrumento de pesquisa e referência para o trabalho ${ }^{3}$. O objetivo com esta última escolha foi incluir no repertório visual dos estudantes não só referências internacionais, como também nacionais/locais, ajudando-os a perceber que a elaboração de um filme não é algo impossível e nem tampouco distante da gente.

As produções construídas foram amparadas por técnicas de sonoplastia, trilha sonora, planos de filmagem e iluminação, viabilizando a construção de um vídeo curta-metragem intitulado '\#Sozinho's (referente à temática bullying).

A produção do vídeo esteve incorporada ao plano de trabalho sem perder de vista os objetivos específicos do projeto que preconizam, dentre outros fatores: o desenvolvimento da criticidade e da responsabilidade social das nossas intervenções no espaço vivido.

Assim, a necessidade de explorarmos uma solução para a questão social que escolhemos trabalhar nos levou a dialogar sobre valores humanos urgentes em diferentes sociedades contemporâneas, capazes de evitar questões como o bullying, a exemplo da tolerância e do respeito às diferenças.

A sinopse a seguir foi elaborada coletivamente e refere-se ao curta-metragem citado.

3 Disponível em: < https://www.youtube.com/watch?v= ${ }_{\mathrm{v}}$ PqpC3L-Vsg > Acesso em: 22 out. 2017.

4 Disponível em: < https://www.youtube.com/watch?v=5ggxWCKGRKw> Acesso em: 22 out. 2017. 


\section{Título do Vídeo: \#Sozinho}

A história expõe dificuldades vividas por um adolescente em meio à falta de amizades no espaço escolar. A construção da narrativa se apoia na dramatização do cotidiano do personagem principal, repleto de situações de bullying e momentos de solidão, cujas consequências comprometem a sociabilização de suas potencialidades que, ao serem descobertas e reveladas por uma amiga de turma, sustentam uma mensagem de empoderamento social e respeito às diferenças.

Vale elucidar que este curta-metragem teve como principal inspiração o videoclipe 'Alone' produzido pelo DJ norte-americano Marshmello, escolha apresentada pelos próprios alunos como referência para o desenvolvimento do vídeo após uma das pesquisas previstas em nossas etapas de trabalho. Uma vez acatada a proposta, amadurecemos a ideia de produzir uma narrativa inspirada no videoclipe Alone, porém, adaptada ao espaço escolar cotidiano dos alunos envolvidos.

Além dos conteúdos específicos da disciplina geografia, explorados em sala de aula antes e após a elaboração do vídeo, houve o cuidado de, durante o processo de produção do mesmo, manter a relação com a disciplina latente. Destarte, propusemos uma analogia entre as etapas que constituem a elaboração de um vídeo curta-metragem com os seguintes métodos de operar da geografia: observar, descrever, representar e explicar.

Relacionamos a etapa 'observar' ao exercício de análises fílmicas, pesquisas realizadas em biblioteca e no ambiente informatizado, além das aulas expositivas sobre os temas e conteúdos envolvidos.

Já a etapa 'descrever' foi aludida ao processo de roteirização dos vídeos curtasmetragens, onde, dentre outras tarefas, os alunos precisaram colocar as ideias no papel, detalhando todas as informações que precisariam representar na encenação.

Assim, a fase do 'representar', não só teve como pré-requisito a conclusão das duas etapas anteriores como também constituiu a materialização das ideias descritas no roteiro, evolvendo as etapas de ensaios e filmagens.

Por fim, mas não menos importante, a etapa 'explicar' pôde ser identificada no momento de sociabilização dos resultados do projeto com a comunidade, não só na modalidade oral e presencial, como também digital, haja vista que além de exibirmos o vídeo para a comunidade escolar e inscrevê-lo num Festival de CurtasMetragens local, publicamos o mesmo no ambiente digital, ampliando o público com o qual os resultados do trabalho foram compartilhados.

\section{Análises dos Resultados}

O processo avaliativo dessa experiência se deu contínua e processualmente, de modo a considerar critérios como: participação e envolvimento do aluno, realização das tarefas propostas e construção de conceitos atrelados aos conteúdos trabalhados. Numa perspectiva 'macro', a associação de conteúdos pedagógicos 
à experiência aqui tratada ressignificou o processo de ensino-aprendizagem dos alunos, ampliando a dimensão disciplinar muitas vezes adotada em instituições de ensino de Educação Básica do país.

Assim, a partir dos objetivos planejados, os resultados alcançados apontaram os seguintes resultados:

No que concerne aos objetivos especificos Estimular a criticidade no que tange às causas e implicações da ação bumana diante do bullying, especialmente no espaço escolar' $\mathrm{e}$ Viabilizar a conscientização sobre a responsabilidade social das nossas escolhas e intervenções no espaço vivido, enquanto cidadãos, considerando direitos e deveres', foi possível verificar mudanças de atitudes entre os estudantes após se inteirarem da legislação que ampara estas questões e dos relatos de colegas que compartilharam circunstâncias já vividas. Uma vez que eles foram municiados de exemplos, relatos e leis relacionadas ao conteúdo, o fator 'responsabilidade', por si e pelo seu meio, foi aguçado. Além disto, a sociabilização dos vídeos-curtas metragens com o público demarcou a contribuição social desses jovens no espaço vivido, uma vez que requereu deles uma postura de quem representa uma atitude cidadã. Dito de outro modo, a responsabilidade de protagonizar uma narrativa visual que propaga a importância do respeito às diferenças, carregou consigo a missão de esses alunos servirem de exemplo do que defendiam: o não ao bullying, papel que eles assumiram com seriedade.

Em relação ao objetivo específico Produఇৃir um vídeo curta-metragem, otimiz̨ando os repertórios tecnológicos e cognitivos dos estudantes ao articular conteúdos curriculares com as especificidades implicadas em uma produção audiovisual', pudemos constatar que a conciliação entre necessidades de ensino e desejos de aprendizagem contribuiu significativamente para que os conceitos geográficos explorados fossem mais facilmente compreendidos pelos alunos ao incorporarmos tecnologias contemporânea à mediação pedagógica. Percebemos que quando o conteúdo 'passa pelo corpo' do aluno, a aprendizagem tem grandes chances de ser mais significativa, pois é como se aquele sujeito, com direito ao espaço, 'tocasse' ou 'experimentasse no corpo' o conteúdo. E quanto mais o saber 'passa' pela experiência dos sentidos, mais 'fundo' ele atinge a memória.

Em relação ao conteúdo específico 'espaço geográfico', foi constatado que os estudantes já não conseguiam mais tratar do assunto dissociado da discussão sobre os direitos e deveres humanos no espaço cotidiano, quesito não explorado por eles na nossa 'roda de conversa' da sondagem inicial. Outro aspecto interessante é que observamos mudança de atitude comportamental desses alunos quando diante de situações de bullying na escola, ao passo que antes do trabalho desenvolvido muitas eram as situações nas quais o fato de o outro 'ser um sujeito com direito a estar no espaço' nem sempre era respeitado. Com a difusão do vídeo curtametragem produzido, toda a comunidade escolar passou a se autovigiar nesse tipo de circunstância, fazendo valer a premissa de que o homem, enquanto sujeito geográfico, é coautor do espaço social no qual está inserido. Assim, após o projeto, 
também foi possível observar que os estudantes começaram a dedicar um olhar mais crítico e investigativo diante do cotidiano.

Uma vez concluído o projeto, além de compartilharmos os resultados com toda a comunidade escolar, estabelecemos uma parceria com o Centro de Ensino e Pesquisa Aplicada à Educação (CEPAE) da Universidade Federal de Goiás (UFG), onde o vídeo '\#Sozinho', dentre outros adotados pela Instituição, foi exibido em um auditório e discutido em salas de aulas de artes visuais no início do II semestre de 2017.

Foi assim que protagonismo, empoderamento social, criatividade e autoestima deram vez à atitude desmotivada e, muitas vezes passiva, que os estudantes apresentavam diante do trabalho pedagógico antes da implementação do projeto.

\section{Consideraçóes Finais}

A articulação entre conhecimentos curriculares e produções audiovisuais que colocam os alunos na posição de sujeitos ativos, protagonistas de uma ideia cujo planejamento também teve a participação deles, começou a despertar o envolvimento necessário para que o processo de ensino-aprendizagem da geografia fosse significativo. Além dos ganhos referentes aos conteúdos geográficos trabalhos, reforçados com a elaboração dos roteiros e encenação, foi possível observar uma melhora potencial na autoestima desses estudantes que começaram a se sentir reconhecidos e empoderados socialmente, dada a possibilidade de terem suas 'vozes' e 'faces', respectivamente ouvidas e vistas por muitos. De tal modo isto procede que no espaço escolar em que estão inseridos, esses alunos foram deslocados de uma posição 'anônima' para o que os colegas de outras turmas chamam de 'famosos', ou, ainda, de espectadores a atores do conhecimento.

Por outro lado, seria muito pretensioso afirmar que este trabalho encerra os problemas relacionados ao bullying na nossa comunidade, cujos desafios presentes se renovam a cada dia na contemporaneidade. Assim, sabemos que esta ação, por si só, não é suficiente para mudar o mundo. Mas talvez seja suficiente para mudar o modo de ser-humano de cada aluno envolvido, habilitando-os a ampliar o processo educativo do qual compartilham, dando o testemunho dos seus respectivos modos de conduzir a vida e as atitudes nos espaços que ocupam.

Por fim, muito embora o uso de tecnologias contemporâneas no contexto escolar não seja garantia de trabalho bem sucedido, o poder de atração e estímulo que essas ferramentas exercem na vida cotidiana podem fazer delas um instrumento didático potencial. Cabe a todos os envolvidos com o processo educacional o papel de mediar o uso desses aparatos tecnológicos, e a interpretação de seus produtos, em prol de uma sociedade mais lúcida e cidadã. O lugar do professor em ações dessa natureza constitui um espaço de extrema responsabilidade. Afinal, seria um grande equívoco pretender atribuir o sucesso ou fracasso de um trabalho pedagógico à presença ou ausência de recursos. $\mathrm{O}$ uso de mídias contemporâneas e produções artísticas tanto poderiam contribuir com um ensino de geografia significativo quanto atrapalhar. A mediação docente, (o que integra as escolhas 
metodológicas, os planejamentos e a atuação em sala), portanto, continua sendo o fator determinante que cerceia todo o desenvolvimento do trabalho do professor.

\section{Referências}

CALVO, Alfredo. Viagem à escola do século XXI: assim trabalham os colégios mais inovadores do mundo. São Paulo: Fundação Telefônica Vivo, 2016;

GANZELA, Marcelo. A escola menos escolarizada. Apostila do Curso Extrapolando as Paredes da Sala de Aula. São Paulo: Instituto Singularidades, 2017;

MITCHELL, William. Não existem mídias visuais. In: DOMINGUES, Diana (Org.). Arte, ciência e tecnologia: passado presente e desafios. São Paulo: UNESP / Itaú Cultural, 2009. p. 167-177;

SANTOS, Milton. Por uma geografia nova. Da crítica da geografia a uma geografia crítica. São Paulo: Edusp, 2004;

TAVARES, Maria Tereza. Uma escola: texto e contexto. In: GARCIA, Regina (Org.). Método: a pesquisa com o cotidiano. Rio de Janeiro: DP\&A, 2003. p. 43-61;

SINGER, Helena (Org.). Territórios educativos: experiências em diálogo com o bairroescola. São Paulo: Moderna, 2015;

VARGAS, Milton (Org.). História da técnica e da tecnologia no Brasil. São Paulo: UNESP, 1995. 